Article

\title{
Temperature Dependent Solid Solution Strengthening in the High Entropy Alloy CrMnFeCoNi in Single Crystalline State
}

\author{
Christian Gadelmeier ${ }^{1}$, Sebastian Haas ${ }^{1}$, Tim Lienig ${ }^{2}$, Anna Manzoni ${ }^{3}{ }^{(0)}$, \\ Michael Feuerbacher ${ }^{2}$ and Uwe Glatzel ${ }^{1, *(D)}$ \\ 1 Metals and Alloys, University of Bayreuth, 95447 Bayreuth, Germany; \\ christian.gadelmeier@uni-bayreuth.de (C.G.); sebastian-haas@uni-bayreuth.de (S.H.) \\ 2 Ernst Ruska-Centre for Microscopy and Spectroscopy with Electrons and Peter Grünberg Institute, \\ Forschungszentrum Jülich GmbH, 52425 Jülich, Germany; t.lienig@fz-juelich.de (T.L.); \\ m.feuerbacher@fz-juelich.de (M.F.) \\ 3 Bundesanstalt für Materialforschung und -prüfung, 12205 Berlin, Germany; anna.manzoni@bam.de \\ * Correspondence: uwe.glatzel@uni-bayreuth.de; Tel.: +49-921-55-6600
}

Received: 2 September 2020; Accepted: 22 October 2020; Published: 23 October 2020

\begin{abstract}
The main difference between high entropy alloys and conventional alloys is the solid solution strengthening effect, which shifts from a single element to a multi-element matrix. Little is known about the effectiveness of this effect at high temperatures. Face-centered cubic, equiatomic, and single crystalline high entropy alloy $\mathrm{CrMnFeCoNi}$ was pre-alloyed by arc-melting and cast as a single crystal using the Bridgman process. Mechanical characterization by creep testing were performed at temperatures of $700,980,1100$, and $1200{ }^{\circ} \mathrm{C}$ at different loads under vacuum and compared to single-crystalline pure nickel. The results allow a direct assessment of the influence of the chemical composition without any disturbance by grain boundary sliding or diffusion. The results indicate different behaviors of single crystalline pure nickel and $\mathrm{CrMnFeCoNi}$. At $700^{\circ} \mathrm{C} \mathrm{CrMnFeCoNi}$ is more creep-resistant than $\mathrm{Ni}$, but at $980^{\circ} \mathrm{C}$ both alloys show a nearly similar creep strength. Above $980^{\circ} \mathrm{C}$ the creep behavior is identical and the solid solution strengthening effect of the $\mathrm{CrMnFeCoNi}$ alloy disappears.
\end{abstract}

Keywords: high entropy alloy; HEA; single crystal; CrMnFeCoNi; creep behavior; solid solution strengthening

\section{Introduction}

During the last 15 years, research in the field of high entropy alloys (HEA) and compositionally complex alloys (CCA) has shown enormous growth [1-4]. Per definition, a HEA is a solid solution crystal consisting of at least five alloying elements in near equiatomic ratio [5] and, therefore, there is no base element dominating the composition. Only a few HEA stand out by not having a multiphase microstructure, but rather a simple disordered solid solution microstructure, which maximizes the configurational entropy $\Delta S_{\text {conf }}$ [6]. The latter is directly linked to the solid solution strengthening behavior in HEA and CCA $[7,8]$. Such alloys have higher strength than pure elements due to the solute atoms dissolved in the solvent matrix which provide resistance to dislocation motion. Solid solution strengthening (often referred in context with lattice distortion and subsequently sluggish diffusion) is a way to increase the strength of a metal by alloying elements [9-13].

A very common high entropy alloy is $\mathrm{CrMnFeCoNi}$, often called Cantor alloy. Previous studies using this alloy focused on polycrystalline structure and on higher temperatures [14-20]. The influence of grains or varying grain size on the mechanical properties of the $\mathrm{CrMnFeCoNi}$ alloy was investigated 
by Sun et al. [20]. With regard to the formation of phase separation and precipitation as a function of temperature, important impact factors have been studied by Joseph and Otto et al. [21,22]. Their work shows that, at intermediate temperatures above $800^{\circ} \mathrm{C}, \mathrm{CrMnFeCoNi}$ shows a single-phase structure after an ageing period of 500 days, but at $700{ }^{\circ} \mathrm{C}$ and below precipitates form exclusively at the grain boundaries and pores [22]. This shows that the choice of temperature is an important factor to consider for long-term mechanical characterization like creep experiments. In addition the diffusion behavior (often referred in relation to sluggish diffusion) of the individual elements in the alloy, for example by bulk and grain boundary diffusion, must also be considered [23,24].

The previous works on CrMnFeCoNi with polycrystalline structure are very application-oriented and tunable by several processes such as grain refinement, cold working, recrystallization or combinations of these. To the moment, there is little knowledge of a state close to the equilibrium, which serves as a base on which all other states can be referred to. This state close to equilibrium can be approximated using an unconstrained single crystal (SX), where no influence of grains or deformation effect the inherent material properties. Therefore, single crystalline CrMnFeCoNi samples allow the investigation of the pure material properties without effects linked to grain boundaries like grain size, grain boundary diffusion or formation of precipitates. So far, mechanical properties on Cantor single crystals have only been carried out in the temperature range of $-196{ }^{\circ} \mathrm{C}$ to $300{ }^{\circ} \mathrm{C}$, both in tension and compression [25-27]. The behavior at temperatures higher than $300{ }^{\circ} \mathrm{C}$ is unknown, yet important to thoroughly understand the material.

To investigate the time-dependent mechanical properties at higher temperatures, creep testing is a suitable method. Creep deformation is a diffusion-controlled mechanism that is activated at temperatures above $40 \%$ of the materials melting temperature $\mathrm{T}_{\mathrm{m}}$. The predominant deformation mechanism is non-conservative dislocation movement by climbing even at very low stress levels. In addition, the effect of solid solution strengthening (in the context with sluggish diffusion kinetics) of two alloys can also be investigated by creep testing, as Fleischmann et al. showed [28] by comparing two Ni-based superalloys by adding Re to one of the two alloys.

The aim of this work is to fill the high temperature knowledge gap by studying the creep properties of a single crystal. This does provide an understanding of the solid solution strengthening and dislocation movement, excluding diffusion and effects at grain boundaries. This will be achieved by comparing two face centered cubic (fcc) single phase single crystals with different configurational entropy: the solid solution CrMnFeCoNi with $\Delta S_{\text {conf }}=1.61 \times R(R=$ universal gas constant 8.314 $\mathrm{J} \mathrm{mol}^{-1} \mathrm{~K}^{-1}$ ) and pure Ni with $\Delta \mathrm{S}_{\text {conf }}=0 \times \mathrm{R}$, which exhibits no solid solution [29].

\section{Materials and Methods}

\subsection{Alloy Fabrication}

Elements with a technical purity of at least $99.99 \%$ were used for the production of the CrMnFeCoNi alloy. In a first step, the elements were melted in an arc-melting furnace (Edmund Bühler $\mathrm{GmbH}$, Bodelshausen, Germany) under argon to form master alloys with a diameter of 35-40 $\mathrm{mm}$ and a height of 7-9 mm. In order to achieve sufficient chemical homogeneity, the ingots were flipped at least six times. All ingots were analyzed by micro X-ray fluorescence ( $\mu$-XRF, AMETEK, Berwyn PA, USA), which shows a homogeneous element distribution of $20 \pm 1.0$ at $\%$ per element. In the second step, a total mass of $400 \mathrm{~g}$ (eight master alloys ingots) is placed in a zirconium oxide crucible and put in the center of a water-cooled copper coil of an induction casting device (Metals and Alloys, University of Bayreuth, Bayreuth, Germany) [30,31]. The ceramic mold with a helical grain selector was heated up to $1450{ }^{\circ} \mathrm{C}\left(100^{\circ} \mathrm{C}\right.$ above the solidus temperature [29]) in a second induction coil. Subsequently, the master alloy is heated in the crucible to approximately $1600{ }^{\circ} \mathrm{C}$ by induction, homogenized in liquid state for $5 \mathrm{~min}$ and cast into the pre-heated ceramic mold. The ceramic mold was pulled through a water-cooled baffle with a speed of $3 \mathrm{~mm} / \mathrm{min}$ resulting in a total solidification time of $1-2 \mathrm{~h}$. The single crystal solidifies in [001] orientation with a maximum deviation of $3^{\circ}$. To prevent manganese loss due 
to evaporation argon $\left(5 \times 10^{4} \mathrm{~Pa}\right)$ was used as atmosphere. Thereby manganese loss does not occur during the single crystal casting process (see Figure 1). In addition, single crystalline pure nickel was cast as in the same way but under vacuum.

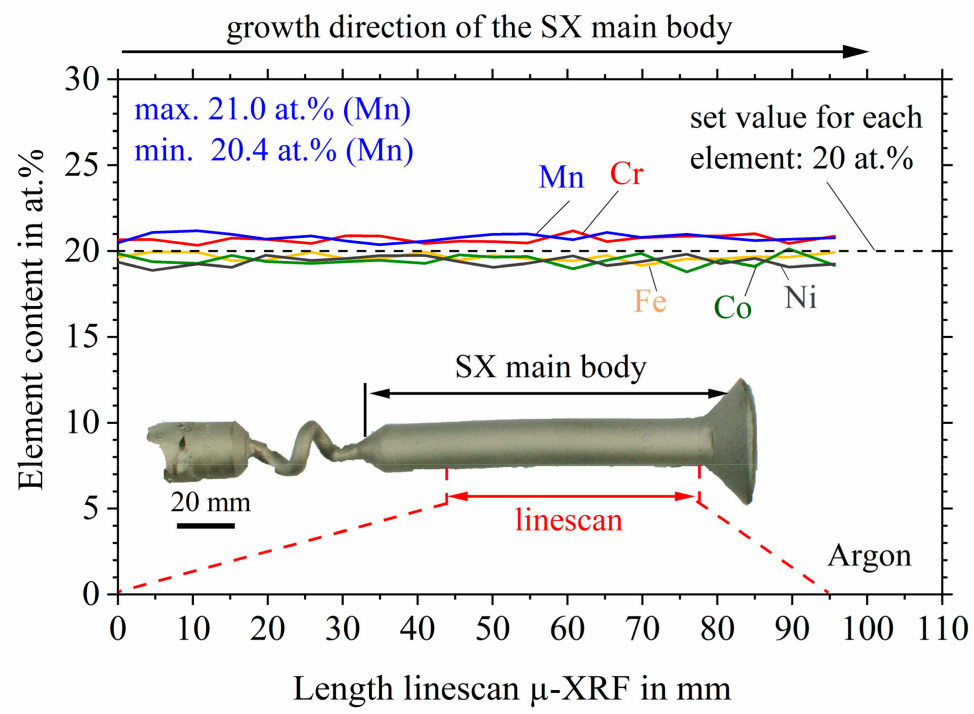

Figure 1. Elemental concentration of the SX-CrMnFeCoNi alloy measured with $\mu$-XRF cast in argon atmosphere.

All single crystalline samples were cast in a cylindrical shape with about $16 \mathrm{~mm}$ in diameter and a length of $170 \mathrm{~mm}$. The samples were sandblasted and etched with a solution of $100 \mathrm{~mL} \mathrm{H}_{2} \mathrm{O}$, $200 \mathrm{~mL} \mathrm{HCl}, 60 \mathrm{~g} \mathrm{FeCl} 3 \cdot 6 \mathrm{H}_{2} \mathrm{O}$ and $12 \mathrm{~g}\left(\mathrm{NH}_{4}\right) 2\left[\mathrm{CuCl}_{4}\right] \cdot 2 \mathrm{H}_{2} \mathrm{O}$ (Adler etch) to remove adhering mold shell residues. The quality check of both single crystals by electron backscatter diffraction (EBSD, AMETEK, Berwyn PA, USA) shows no further grains and a crystallographic orientation of [001] $\pm 3^{\circ}$ for $\mathrm{CrMnFeCoNi}$ and $8^{\circ}$ for pure $\mathrm{Ni}$.

To verify the equiatomic composition of the cast CrMnFeCoNi alloy, the sample was ground along the sample length with $\mathrm{SiC}$ paper 320 to obtain a plane surface for $\mu$-XRF measurement (linescan). Figure 1 shows a constant equiatomic distribution with $20 \pm 1.0$ at $\%$ for each element of the sample cast in argon atmosphere. The measurement was carried out on the SX main body of the sample. In comparison, the use of vacuum as process atmosphere leads to an inhomogeneous element distribution, because of the evaporation of manganese [23,24].

\subsection{Sample Preparation}

Creep samples for mechanical testing were prepared by wire electronic discharge machining (EDM). All creep samples were etched with V2 etch, a solution of $100 \mathrm{~mL} \mathrm{HCl}, 100 \mathrm{~mL} \mathrm{H} \mathrm{H}_{2}, 10 \mathrm{~mL}$ $\mathrm{HNO}_{3}$ and $1 \mathrm{~mL}$ pickling solution, to remove the remaining layer of wire EDM and with the side effect of bringing out the dendritic structure. Before testing, the samples were ground with $\mathrm{SiC}$ paper 2400. The samples had a rectangular cross-section of $1.0 \times 2.9 \mathrm{~mm}$, a measuring length of $5 \mathrm{~mm}$, and a total length of $30 \mathrm{~mm}$ and were similar to the geometry reported in [32].

\subsection{Mechanical Testing}

Creep tests were carried out under vacuum $\left(2 \times 10^{-4} \mathrm{~Pa}\right)$ using a vacuum creep testing device (Metals and Alloys, University of Bayreuth, Bayreuth, Germany) as described in [33]. The tests were performed at high temperatures of $700,980,1100$, and $1200{ }^{\circ} \mathrm{C}$, controlled by a type-S thermocouple close to the sample. The specimens were griped by $\mathrm{Al}_{2} \mathrm{O}_{3}$ rods and heated up to the test temperature with a rate of $20 \mathrm{~K} / \mathrm{min}$ in a resistance-heated furnace. The strain was measured by non-contacting 
video extensometer [34]. The load was chosen in the range of 2-125 MPa in order to achieve stationary creep rates in a wide range of $10^{-8}-10^{-3} \mathrm{~s}^{-1}$. As a starting point for determination of the creep loads, the yield strength of tensile tests according to [35] were determined with an strain rate of $10^{-3} \mathrm{~s}^{-1}$ at 700 and $1000{ }^{\circ} \mathrm{C}$ using the same sample geometry. This test resulted in a yield strength of $46 \mathrm{MPa}$ at $700{ }^{\circ} \mathrm{C}$ and $7 \mathrm{MPa}$ at $1000^{\circ} \mathrm{C}$ for pure nickel and $62 \mathrm{MPa}$ at $700{ }^{\circ} \mathrm{C}$ and $42 \mathrm{MPa}$ at $1000{ }^{\circ} \mathrm{C}$ for $\mathrm{CrMnFeCoNi}$.

\section{Results and Discussion}

The applied creep loads were selected below the yield strengths from tensile tests at 700 and $1000{ }^{\circ} \mathrm{C}$. For all investigated creep samples, the strains in the primary and secondary creep range were uniform along the specimen length. In the tertiary area up to the failure, there is only deformation along the gauge length between the ridges. The following results show the deformation as an engineering strain.

The creep results for $\mathrm{CrMnFeCoNi}$ (red) and pure nickel (blue) are plotted as creep rate over strain at $700{ }^{\circ} \mathrm{C}$ in Figures 2 and 3 and at $980{ }^{\circ} \mathrm{C}$ in Figure 4 . At $700{ }^{\circ} \mathrm{C}$ testing temperature, the tests at 50 and $65 \mathrm{MPa}$ for $\mathrm{CrMnFeCoNi}$ (Figure 2a) and at $20 \mathrm{MPa}$ for pure nickel (Figure 2b) were interrupted for further investigations (marked with open circles). At $980{ }^{\circ} \mathrm{C}$ the test at $8 \mathrm{MPa}$ for $\mathrm{CrMnFeCoNi}$ (Figure 4a) and 5, 8, and $9 \mathrm{MPa}$ for pure nickel (Figure $4 \mathrm{~b}$ ) were interrupted. All other tests were carried out until fracture (marked with black crosses in Figures 2 and 4). The strain to failure was in almost all cases higher than $30 \%$. At both temperatures, the minimum creep rate of pure nickel is achieved at higher strain levels, i.e., much higher than $2 \%$. The minimum creep rate of the $\mathrm{CrMnFeCoNi}$ alloy is always reached at less than $2 \%$ strain at both temperatures. This effect may be based on the different deviations of the two singe crystals from the [001] orientation. The deviation from the [001] orientation of the pure nickel samples was $8^{\circ}$ and therefore $5^{\circ}$ higher than that of the CrMnFeCoNi samples. Primary creep is known to be sensitive to orientation [36-39]: Deviations from the [001] axis, which are close to the [001]-[111] diagonal, resulting in an increased primary creep regime.

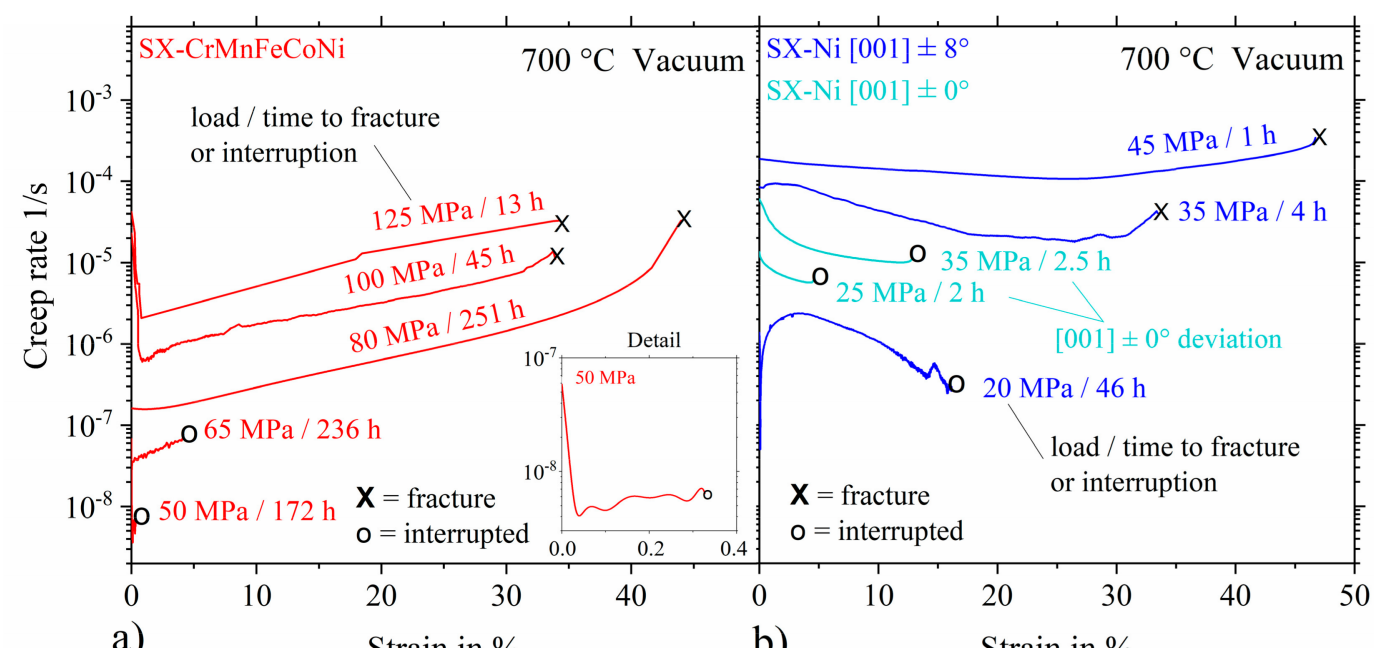

Figure 2. Creep rate over strain diagram for vacuum creep tests at $700{ }^{\circ} \mathrm{C}$ of the single crystalline (a) CrMnFeCoNi alloy, and (b) pure nickel with a detail of the $50 \mathrm{MPa}$ curve of the CrMnFeCoNi alloy in the inset.

Perfectly oriented SX-Ni creep samples with a deviation of the orientation of [001] $\pm 0^{\circ}$ were prepared and tested at a temperature of $700{ }^{\circ} \mathrm{C}$ to investigate the influence of the orientation deviation on the minimum creep rate. Figure $2 b$ shows the results of these creep tests as light blue creep curves for 25 and $35 \mathrm{MPa}$ loads. In both cases the tests show a normal, not pronounced primary creep behavior. The minimum creep rate of both tests is reached earlier than for the Ni samples with $8^{\circ}$ deviation. Figure 3 shows the comparison of the creep results for $0^{\circ}$ and $8^{\circ}$ deviation samples at a load 
of $35 \mathrm{MPa}$ in more detail. For $8^{\circ}$ deviation the minimum creep rate of $1.8 \times 10^{-5} 1 / \mathrm{s}$ is achieved at $26 \%$ strain, whereas for $0^{\circ}$ deviation it is already achieved after $11 \%$ at a similar creep rate of $1.0 \times 10^{-5} 1 / \mathrm{s}$ (Figure 3a). This shows that primary creep behavior (Figure 3b) is sensitive to orientation, but without any influence on the minimum creep rate.

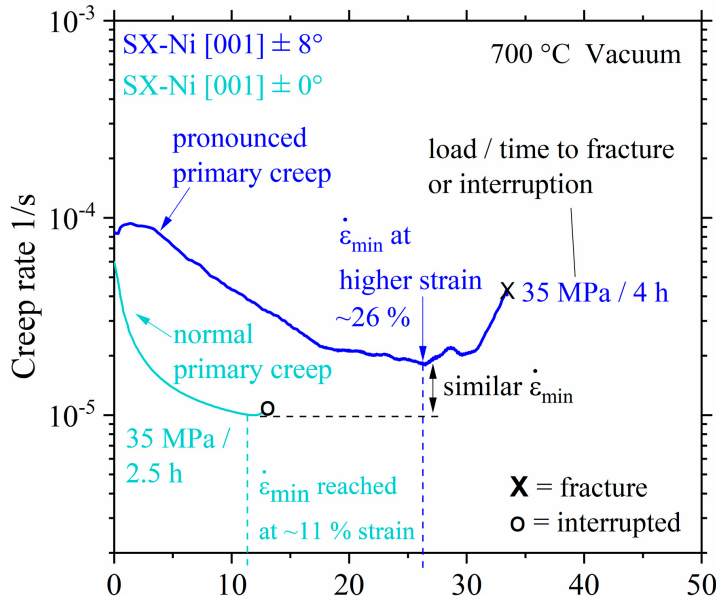

a)
Strain in \%

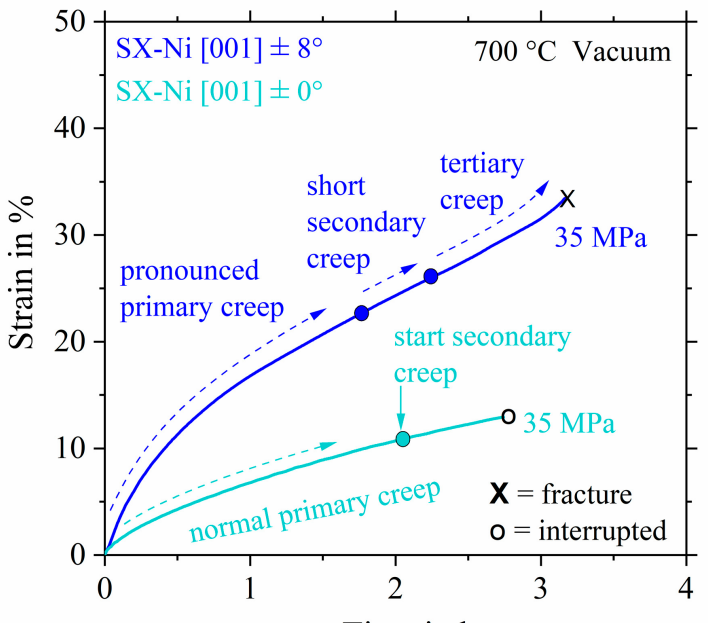

b)

Time in $\mathrm{h}$

Figure 3. Influence of deviation from exact orientation [001] of pure $\mathrm{Ni}$ at $700{ }^{\circ} \mathrm{C},(\mathbf{a})$ creep rate over strain (extracted from Figure 2b), and (b) strain over time.

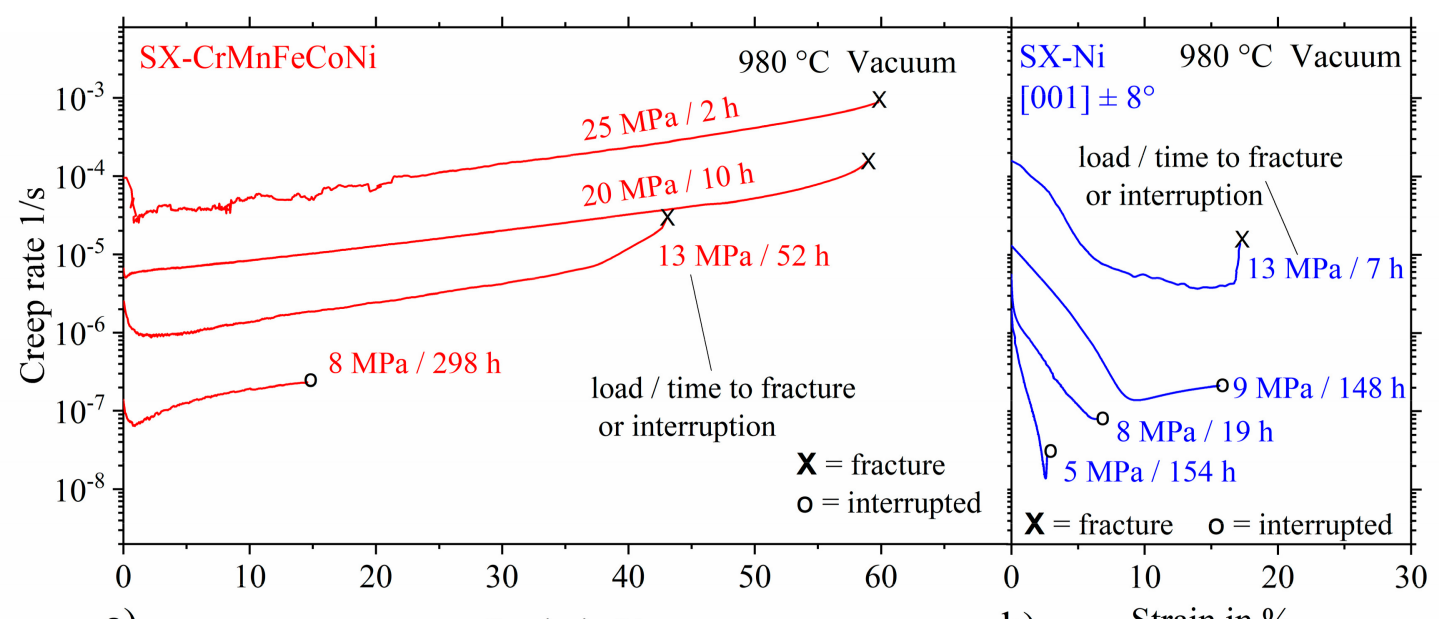

a)

Strain in $\%$

b) Strain in $\%$

Figure 4. Creep rate over strain diagram for the creep tests of the single crystalline (a) $\mathrm{CrMnFeCoNi}$ alloy, and (b) pure nickel at $980^{\circ} \mathrm{C}$ and at different loads under vacuum.

Figures 5 and 6 show the creep results for pure nickel and $\mathrm{CrMnFeCoNi}$ at $1100{ }^{\circ} \mathrm{C}$ and $1200{ }^{\circ} \mathrm{C}$, respectively. All tests were started with a stress level of $2 \mathrm{MPa}$. Afterwards, the stress was increased stepwise up to $8 \mathrm{MPa}$ at $1100^{\circ} \mathrm{C}$ and $10 \mathrm{MPa}$ at $1200{ }^{\circ} \mathrm{C}$, whenever it was obvious that the minimum creep rate was reached. The stepwise stress increase at the temperature of $1100{ }^{\circ} \mathrm{C}$ was identical for both materials (Figure $5 \mathrm{a}, \mathrm{b}$ ). For each increase, the reduction of the specimen cross-section $\mathrm{A}_{0 \text {-new }}$ was calculated (equation in Figure 5). $A_{0}$ is the initial cross section of the specimen, $A_{0-n e w}$ is the difference between $\mathrm{A}_{0}$ and $\mathrm{A}_{\text {new }}$ and $\varepsilon_{\text {load before }}$ is the achieved strain until load increase. Thus, the strain up to the load increase was considered. 


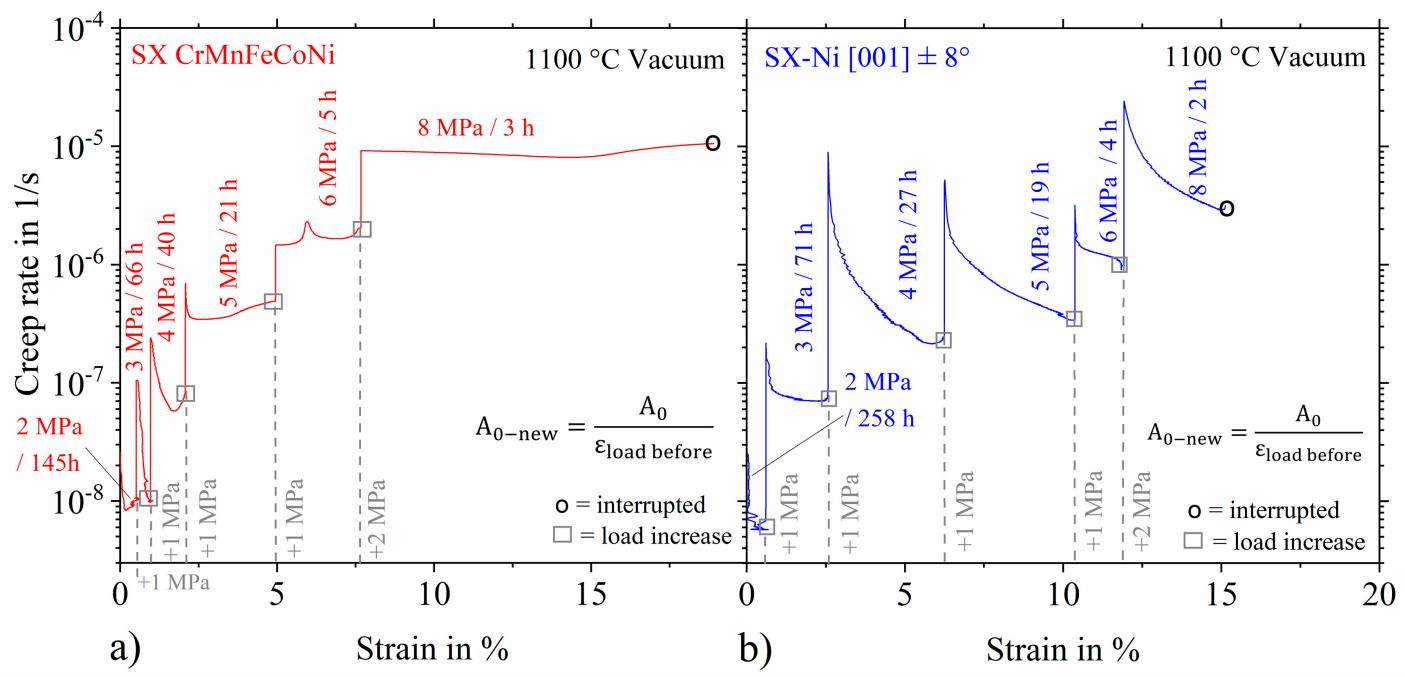

Figure 5. Creep rate over strain diagrams for the creep tests of the single crystalline (a) CrMnFeCoNi alloy, and (b) pure nickel at $1100{ }^{\circ} \mathrm{C}$ and with different stress levels by stress increase under vacuum.

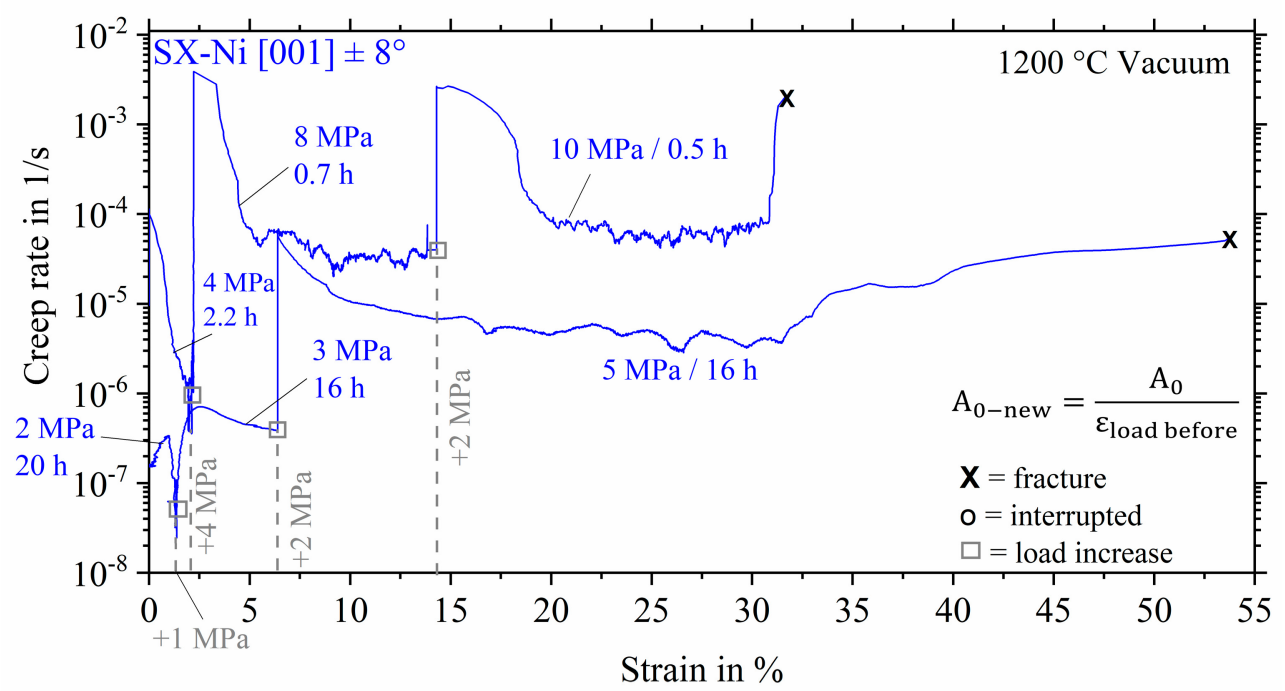

Figure 6. Creep rate over strain diagram for the creep tests of the single crystalline pure nickel at $1200{ }^{\circ} \mathrm{C}$ with different stress levels by using stress increase under vacuum.

Both tests at $1100^{\circ} \mathrm{C}$ were interrupted, the one in pure nickel after $358 \mathrm{~h}$ and the one in $\mathrm{CrMnFeCoNi}$ after 280 h. At $1200{ }^{\circ} \mathrm{C}$ (Figure 6), two pure Ni specimens were tested with a stepwise load increase until fracture. The testing times were $3.5 \mathrm{~h}$ and $45 \mathrm{~h}$. Due to high evaporation rates of manganese, no creep tests could be carried out for $\mathrm{CrMnFeCoNi}$ at this high temperature.

Based on the creep results plotted in Figures 2-6 the minimum creep rate $\dot{\varepsilon}_{\text {min }}$ is determined using Equation (1) and listed in Table 1 (where $n$ is called Norton exponent or stress exponent). Using a double-logarithmic scaling, the minimum creep rate $\dot{\varepsilon}_{\text {min }}$ is plotted over the applied stress $\sigma$ (Norton plot, Figure 7). Both pure nickel and CrMnFeCoNi show a linear relationship between these two parameters.

$$
\dot{\varepsilon}_{\min }=\sigma^{\mathrm{n}}
$$


Table 1. Minimum creep rates and stress exponents for the creep tests of pure nickel and $\mathrm{CrMnFeCoNi}$ at different loads and temperatures under vacuum.

\begin{tabular}{|c|c|c|c|c|c|c|c|}
\hline \multirow{3}{*}{$\begin{array}{c}\text { Material } \\
\text { Temperature in }{ }^{\circ} \mathrm{C}\end{array}$} & \multicolumn{7}{|c|}{$\log _{10} \dot{\mathcal{E}}_{\min }$ in $\mathrm{s}^{-1}$} \\
\hline & \multicolumn{4}{|c|}{ SX-Ni } & \multicolumn{3}{|c|}{ SX-CrMnFeCoNi } \\
\hline & 700 & 980 & 1100 & 1200 & 700 & 980 & 1100 \\
\hline \multicolumn{8}{|l|}{ Load in MPa } \\
\hline 2 & & & -8.2 & -7.4 & & & -8.1 \\
\hline 3 & & & -7.5 & -6.4 & & & -7.9 \\
\hline 4 & & & -6.7 & -6.0 & & & -7.1 \\
\hline 5 & & -7.7 & -6.4 & -5.5 & & & -6.5 \\
\hline 6 & & & -6.0 & & & & -5.8 \\
\hline 8 & & -7.1 & -5.5 & -4.5 & & -7.2 & -5.1 \\
\hline 9 & & -6.8 & & -4.2 & & & \\
\hline 13 & & -5.5 & & & & -6.0 & \\
\hline 20 & -6.5 & & & & & -5.2 & \\
\hline 25 & $-5.3^{1}$ & & & & & -4.6 & \\
\hline 35 & $-4.8 /-5.0^{1}$ & & & & & & \\
\hline 45 & -4.0 & & & & & & \\
\hline 50 & & & & & -8.3 & & \\
\hline 65 & & & & & -7.6 & & \\
\hline 80 & & & & & -6.8 & & \\
\hline 100 & & & & & -6.3 & & \\
\hline 125 & & & & & -5.6 & & \\
\hline Norton exp. $n$ & 7.3 & 5.3 & 4.5 & 4.8 & 6.8 & 5.0 & 5.3 \\
\hline
\end{tabular}

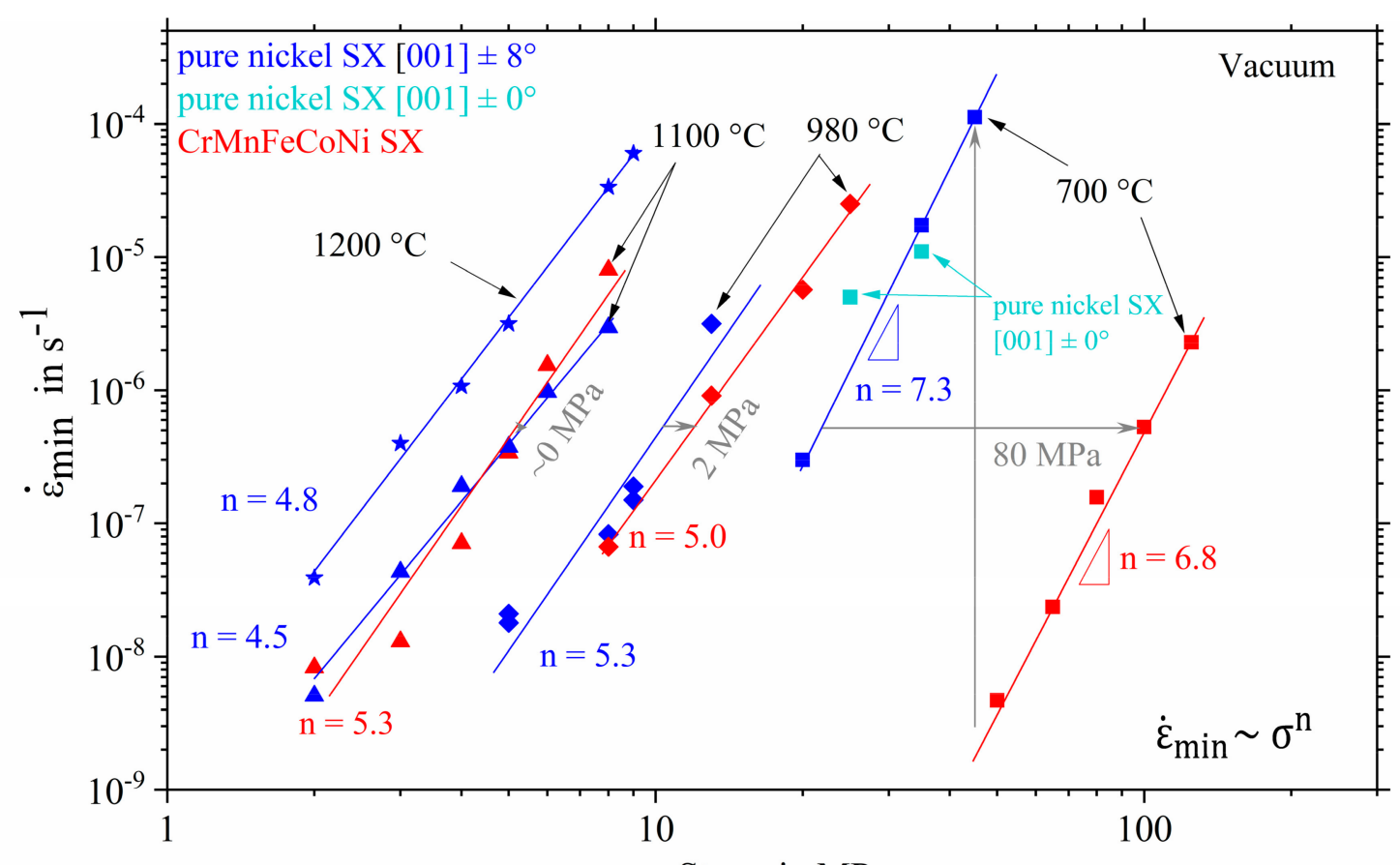

Stress in $\mathrm{MPa}$

Figure 7. Double logarithmic scaling of minimum creep rate over stress of the single crystalline CrMnFeCoNi alloy in comparison to the single crystalline pure nickel (with $0^{\circ}$ and $8^{\circ}$ deviation from [001]) at $700,980,1100$, and $1200{ }^{\circ} \mathrm{C}$ under vacuum. 
It is known that for a stress exponent $\mathrm{n} \approx 1$, volume or grain boundary diffusion are dominating, and for $\mathrm{n}=3-5$ the single-phase material deforms by dislocation climb [40,41]. The Norton exponents of pure nickel and $\mathrm{CrMnFeCoNi}$ at $980^{\circ} \mathrm{C}$ are almost identical, i.e., $\mathrm{n}=5.3$ for nickel and 5.0 for the Cantor alloy. At $1100{ }^{\circ} \mathrm{C}$ the stress exponents are also close to each other, i.e., $\mathrm{n}=4.5$ for pure nickel and 5.3 for the $\mathrm{CrMnFeCoNi}$ alloy. Furthermore, for both temperatures, there is nearly no difference in the stress level (horizontal displacement) between the two materials at the same creep rate. At $1100{ }^{\circ} \mathrm{C}$ the difference is $0 \mathrm{MPa}$ and at $980^{\circ} \mathrm{C}$ only $2 \mathrm{MPa}$. Thus, there is only a very small effect of solid solution strengthening in the $\mathrm{CrMnFeCoNi}$ alloy in comparison to pure $\mathrm{Ni}$ at $980{ }^{\circ} \mathrm{C}$ and no solid solution strengthening at $1100{ }^{\circ} \mathrm{C}$.

At a temperature of $700{ }^{\circ} \mathrm{C}$ a considerable difference in the horizontal displacement of the creep resistance can be detected between pure nickel and $\mathrm{CrMnFeCoNi}$, despite $\mathrm{n}$ being very close $(7.3 \mathrm{for}$ pure $\mathrm{Ni}$ and 6.8 for the $\mathrm{CrMnFeCoNi}$ alloy). The minimum creep rates of the tested $\mathrm{Ni}$ samples (light blue dots) at $700{ }^{\circ} \mathrm{C}$ with a deviation from [001] $\pm 0^{\circ}$, are in the same range as the results of $\mathrm{Ni}$ with $8^{\circ}$ deviation. For pure $\mathrm{Ni}$ a measurement at $50 \mathrm{MPa}$ was not possible, because $45 \mathrm{MPa}$ is already in the range of the yield strength and conventional dislocation glide takes place. Therefore, the creep rate of $1 \times 10^{-4} 1 / \mathrm{s}$ is already in the range as tensile tests and the time to failure was less than $0.1 \mathrm{~h}$. The plotted line of pure $\mathrm{Ni}$ was extrapolated to a value of $50 \mathrm{MPa}$ to compare it with CrMnFeCoNi. The minimum creep rate of pure nickel is more than three orders of magnitude higher than that of $\mathrm{CrMnFeCoNi}$ at $50 \mathrm{MPa}$ : The necessary stress for achieving a minimum creep rate $\dot{\varepsilon}_{\text {min }}$ of $1 \times 10^{-6} \mathrm{~s}^{-1}$ is $80 \mathrm{MPa}$ higher for $\mathrm{CrMnFeCoNi}$ than for pure Ni.

At the lower temperature of $700{ }^{\circ} \mathrm{C}$ solid solution strengthening (in the context to sluggish diffusion) based on a high configurational entropy is, therefore, particularly more effective than at 980 and $1100^{\circ} \mathrm{C}$.

The Larson-Miller plot (Figure 8a) compares the time necessary for reaching $2 \%$ strain $\left(\mathrm{t}_{2} \%\right.$ in $\mathrm{h}$ ) for the different temperatures $700,980,1100$ and $1200{ }^{\circ} \mathrm{C}$ and stress levels. The time to reach $2 \%$ strain is more relevant in the field of application and better reproducible than the time to failure. Equation (2) is used to calculate the Larson-Miller parameter $\mathrm{P}_{2 \%}$, where $\mathrm{T}$ is the temperature in $\mathrm{K}$ :

$$
\mathrm{P}_{2 \%}=\frac{\mathrm{T}}{1 \mathrm{~K}} \times\left(20+\log \frac{\mathrm{t}_{2 \%}}{1 \mathrm{~h}}\right) \times 10^{-3}
$$

The values determined for $t_{2 \%}$ are listed in Table 2 . For the tests using stress increase only the values up to a total strain of $5 \%$ were determined. At low loads of $2 \mathrm{MPa}$, the load increases were carried out before the $2 \%$ limit was reached, because the minimum creep rate was achieved. Therefore, the time to reach $2 \%$ were extrapolated. Both pure nickel and $\mathrm{CrMnFeCoNi}$ show a linear behavior at different slopes. For pure nickel the slope is -0.09 and for $\mathrm{CrMnFeCoNi}$ it is -0.15 . The results of the $\mathrm{Ni}$ samples with the deviation from [001] $\pm 0^{\circ}$ lie in the same range as the results of the samples with $8^{\circ}$ deviation. The straight lines diverge at lower temperature (or increasing stress level). This is due to the increasing solid solution strengthening effect with decreasing temperature. At higher temperatures above $980^{\circ} \mathrm{C}$ and a low load of $2 \mathrm{MPa}$ the point of intersection of both materials can be identified. The value for the Larson-Miller parameter $\mathrm{P}_{2} \%$ at this point is 31.7 .

The use of the absolute temperature for the Larson-Miller plot is particularly suitable in case for possible applications. However, for a pure scientific consideration the use of the homologous temperature of both materials is more suitable. The homologous temperatures $\mathrm{T}_{\mathrm{H}}$ can be determined by $\mathrm{T}_{\mathrm{H}}=\frac{\mathrm{T}}{\mathrm{T}_{\mathrm{m}}}$ using the melting points $\mathrm{T}_{\mathrm{m}}$ for both materials, with $1607 \mathrm{~K}$ for CrMnFeCoNi and $1728 \mathrm{~K}$ for pure Ni. By changing $\mathrm{T}$ to $\mathrm{T} / \mathrm{T}_{\mathrm{m}}$ in Equation (2), the Larson-Miller parameter for homologous temperature can be calculated. 
Table 2. Time to reach $2 \%$ strain for the creep tests in pure nickel and CrMnFeCoNi at different loads and temperatures under vacuum.

\begin{tabular}{|c|c|c|c|c|c|c|c|}
\hline \multirow{3}{*}{$\frac{\text { Material }}{\text { Temperature in }{ }^{\circ} \mathrm{C}}$} & \multicolumn{7}{|c|}{$t_{2 \%}$ in $h$} \\
\hline & \multicolumn{4}{|c|}{ SX-Ni } & \multicolumn{3}{|c|}{ SX-CrMnFeCoNi } \\
\hline & 700 & 980 & 1100 & 1200 & 700 & 980 & 1100 \\
\hline \multicolumn{8}{|l|}{ Load in $\mathrm{MPa}$} \\
\hline 2 & & & 740.7 & $28.4^{2}$ & & & $564.4^{2}$ \\
\hline 3 & & & 70.8 & 6.7 & & & $289.5^{2}$ \\
\hline 4 & & & 9.5 & 1.5 & & & $72.0^{2}$ \\
\hline 5 & & 32.0 & & & & & 15.2 \\
\hline 8 & & 1.5 & & & & 72.0 & \\
\hline 9 & & 0.7 & & & & & \\
\hline 13 & & 0.1 & & & & 5.0 & \\
\hline 20 & 3.1 & & & & & 1.0 & \\
\hline 25 & $0.8^{1}$ & & & & & 0.2 & \\
\hline 35 & $0.1 / 0.2^{1}$ & & & & & & \\
\hline 45 & $<0.1$ & & & & & & \\
\hline 50 & & & & & $830.0^{2}$ & & \\
\hline 65 & & & & & 130.0 & & \\
\hline 80 & & & & & 35.0 & & \\
\hline 100 & & & & & 3.5 & & \\
\hline 125 & & & & & 0.3 & & \\
\hline
\end{tabular}

${ }^{1}$ Creep samples with deviation from $[001] \pm 0^{\circ} .{ }^{2}$ Extrapolated after reaching the minimum creep rate.

The Larson-Miller plot as a function of $\mathrm{T}_{\mathrm{H}}$ is shown in Figure 8b. As already shown in Figure 8a, there exists also a difference in the slope of materials, -0.16 for pure nickel and -0.24 for CrMnFeCoNi. The characteristic feature between Figure $8 \mathrm{a}, \mathrm{b}$ is a shift to the left of pure Ni, which increases the difference between the two materials from $80 \mathrm{MPa}$ (Figure $8 \mathrm{a}$ ) to $105 \mathrm{MPa}$ (Figure $8 \mathrm{~b}$ ).

Assuming a constant load and the same time for $\mathrm{t}_{2 \%}$ of $10 \mathrm{~h}$, the temperature difference between the two materials can be determined from Figure 8b. At $50 \mathrm{MPa}$, the CrMnFeCoNi alloy requires $198 \mathrm{~K}$ more than pure $\mathrm{Ni}$ to achieve a strain of $2 \%$ in the same time. This difference decreases to higher temperatures, therefore, at $3 \mathrm{MPa}$ there is only a difference of $37 \mathrm{~K}$.

The statement is finally identical to the conclusion from the plot using the absolute temperature: at lower temperatures the solid solution strengthening increases.

In order to get an overview of the dislocation structure of both materials, selected interrupted creep samples will be examined using electron channeling contrast imaging (ECCI). The results of this microstructural analysis will be correlated with the mechanical properties. This will be used to determine if there are any fundamental differences in dislocation movement between the Cantor alloy and pure nickel. In case of the low stresses and the resulting stress exponents of $4 \leq n \leq 7$, a stress assisted dislocation climb controlled by lattice diffusion can be expected for CrMnFeCoNi [42]. 


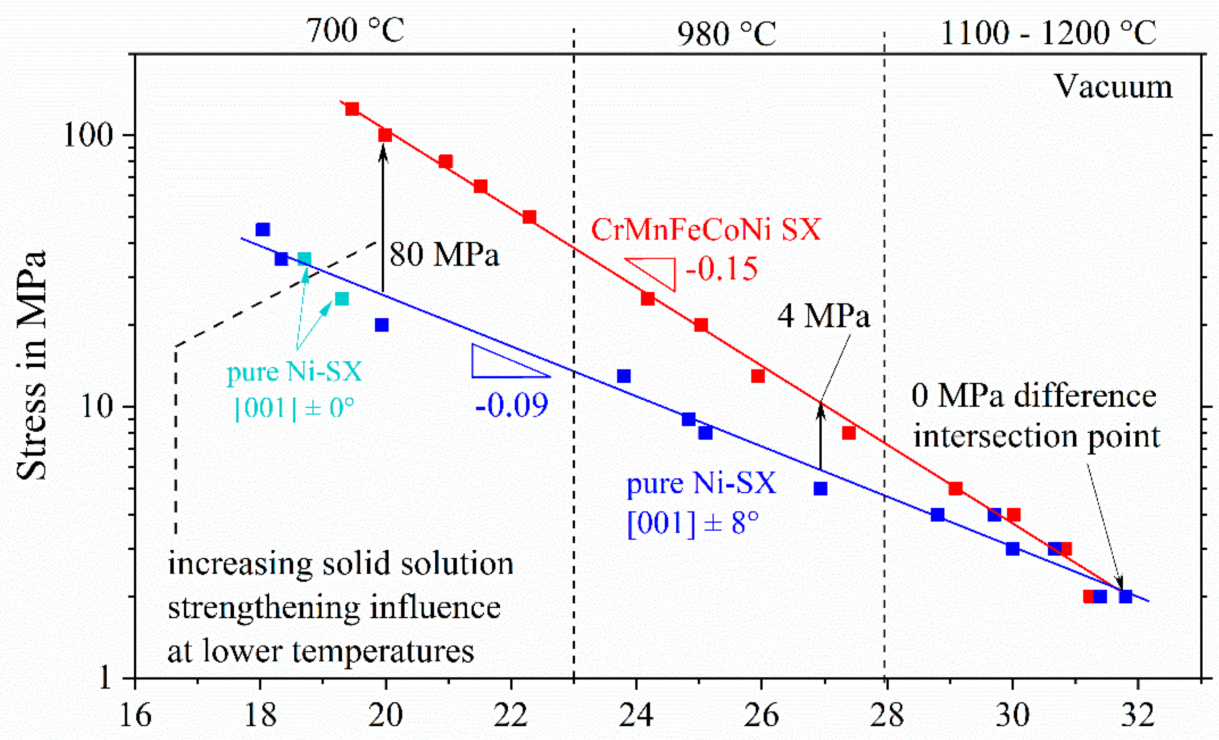

a) Larson-Miller parameter $P_{2} \%=\frac{T}{K} \cdot\left(20+\log \frac{t_{2} \%}{h}\right) \cdot 10^{-3}$

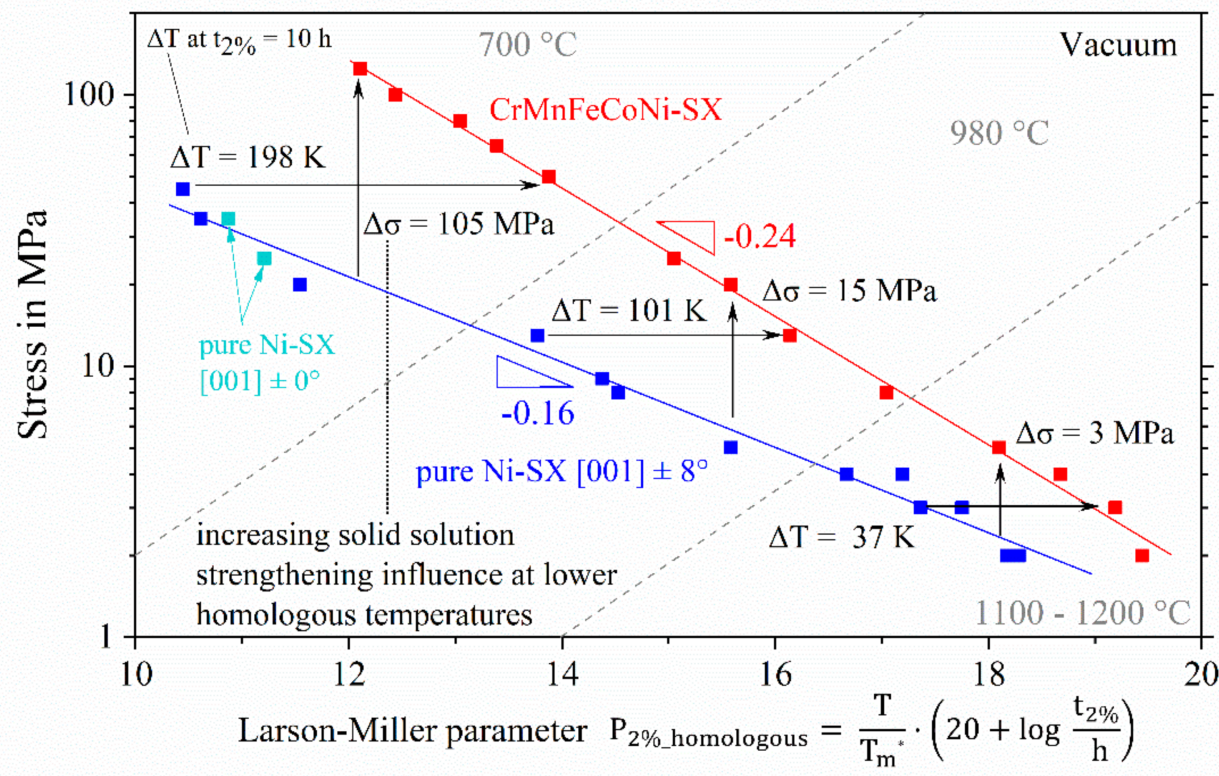

b) in case of $\mathrm{Ni}: \mathrm{T}_{\mathrm{m}}{ }^{*}=\mathrm{T}_{\mathrm{m}}{ }^{\mathrm{Ni}}=1728 \mathrm{~K}$ in case of $\mathrm{CrMnFeCoNi}: \mathrm{T}_{\mathrm{m}}{ }^{*}=\mathrm{T}_{\mathrm{m}}{ }^{\mathrm{CrMnFeCoNi}}=1607 \mathrm{~K}$

Figure 8. Larson-Miller plot of the CrMnFeCoNi alloy compared with pure nickel under vacuum: (a) using absolute temperature, and (b) using homologous temperature. The time to reach $2 \%$ strain was used to calculate the Larson-Miller parameter $\mathrm{P}_{2 \%}$ and $\mathrm{P}_{2} \%$ homologous.

\section{Conclusions}

In summary, the following conclusions can be drawn for the mechanical characterization of CrMnFeCoNi alloy and pure nickel as single crystals:

1. Creep testing of single crystals under vacuum allows a comparison of pure solid solution strengthening, excluding oxidation effects, grain size effects, grain boundary sliding, diffusion, and no precipitate effects.

2. The $8^{\circ}$ deviation from the [001] orientation for SX-Ni leads to an orientation sensitive primary creep behavior compared to $[001] \pm 0^{\circ}$, but there is no detected effect on the minimum creep rate. 
3. The SX CrMnFeCoNi alloy has a strong solid solution strengthening effect at $700{ }^{\circ} \mathrm{C}$ compared to SX pure nickel. The stress necessary to reach the same creep rate is $80 \mathrm{MPa}$ higher in $\mathrm{CrMnFeCoNi}$ than in Ni.

4. The solid solution strengthening effect due to high configurational entropy depends on the temperature and is strongly reduced at $980^{\circ} \mathrm{C}$ and no longer present at $1100{ }^{\circ} \mathrm{C}$.

Author Contributions: Conceptualization: U.G., C.G., and S.H.; methodology: C.G., S.H.; software: C.G.; validation: C.G., S.H., and T.L.; formal analysis: C.G., S.H., and T.L.; investigation: C.G., S.H.; resources: C.G., S.H., and T.L.; data curation: C.G., S.H., and T.L.; writing—original draft preparation: C.G.; writing—review and editing: C.G., S.H., A.M., M.F., and T.L.; visualization: C.G. and S.H.; supervision: U.G. and M.F.; project administration: U.G.; funding acquisition: U.G. and M.F. All authors have read and agreed to the published version of the manuscript.

Funding: This research work was funded by the German Research Foundation (DFG) during project GL 181/56-1 and FE 571/4-1 within the priority program SPP2006 "Compositionally Complex Alloys-High Entropy Alloys (CCA-HEA)" and the project MA 7004/1-1.

Conflicts of Interest: The authors declare no conflict of interest.

\section{References}

1. Murty, B.C.; Yeh, J.W.; Ranganathan, S. High-Entropy Alloys; Elsevier: London, UK, 2014; ISBN 9780128002513.

2. Zhang, W.; Liaw, P.K.; Zhang, Y. Science and technology in high-entropy alloys. Sci. China Mater. 2018, 61, 2-22. [CrossRef]

3. George, E.P.; Raabe, D.; Ritchie, R.O. High-entropy alloys. Nat. Rev. Mater. 2019, 4, 515-534. [CrossRef]

4. Miracle, D.B.; Senkov, O.N. A critical review of high entropy alloys and related concepts. Acta Mater. 2017, 122, 448-511. [CrossRef]

5. Yeh, J.-W.; Chen, S.-K.; Lin, S.-J; Gan, J.-Y.; Chin, T.-S.; Shun, T.-T.; Tsau, C.-H.; Chang, S.-Y. Nanostructured High-Entropy Alloys with Multiple Principal Elements: Novel Alloy Design Concepts and Outcomes. Adv. Eng. Mater. 2004, 6, 299-303. [CrossRef]

6. Ye, Y.F.; Wang, Q.; Lu, J.; Liu, C.T.; Yang, Y. High-entropy alloy: Challenges and prospects. Mater. Today 2016, 19, 349-362. [CrossRef]

7. Yeh, J.-W. Recent progress in high-entropy alloys. Ann. Chim. Sci. Mater. 2006, 31, 633-648. [CrossRef]

8. Fantin, A.; Lepore, G.O.; Manzoni, A.M.; Kasatikov, S.; Scherb, T.; Huthwelker, T.; d'Acapito, F.; Schumacher, G. Short-range chemical order and local lattice distortion in a compositionally complex alloy. Acta Mater. 2020. [CrossRef]

9. Okamoto, N.L.; Yuge, K.; Tanaka, K.; Inui, H.; George, E.P. Atomic displacement in the CrMnFeCoNi high-entropy alloy-A scaling factor to predict solid solution strengthening. AIP Adv. 2016. [CrossRef]

10. Ma, D.; Friák, M.; Von Pezold, J.; Neugebauer, J.; Raabe, D. Ab initio study of compositional trends in solid solution strengthening in metals with low Peierls stresses. Acta Mater. 2015. [CrossRef]

11. Ma, D.; Friák, M.; Von Pezold, J.; Raabe, D.; Neugebauer, J. Computationally efficient and quantitatively accurate multiscale simulation of solid-solution strengthening by ab initio calculation. Acta Mater. 2015. [CrossRef]

12. Leyson, G.P.M.; Curtin, W.A.; Hector, L.G.; Woodward, C.F. Quantitative prediction of solute strengthening in aluminium alloys. Nat. Mater. 2010. [CrossRef]

13. Nabarro, F.R.N. The mechanical properties of metallic solid solutions. Proc. Phys. Soc. 1946. [CrossRef]

14. Otto, F.; Dlouhý, A.; Somsen, C.; Bei, H.; Eggeler, G.; George, E.P. The influences of temperature and microstructure on the tensile properties of a CoCrFeMnNi high-entropy alloy. Acta Mater. 2013, 61, 5743-5755. [CrossRef]

15. Gali, A.; George, E.P. Tensile properties of high- and medium-entropy alloys. Intermetallics 2013, 39, 74-78. [CrossRef]

16. Wu, Z.; Bei, H.; Otto, F.; Pharr, G.M.; George, E.P. Recovery, recrystallization, grain growth and phase stability of a family of FCC-structured multi-component equiatomic solid solution alloys. Intermetallics 2014, 46, 131-140. [CrossRef] 
17. Otto, F.; Hanold, N.L.; George, E.P. Microstructural evolution after thermomechanical processing in an equiatomic, single-phase CoCrFeMnNi high-entropy alloy with special focus on twin boundaries. Intermetallics 2014, 54, 39-48. [CrossRef]

18. Bin Kang, Y.; Shim, S.H.; Lee, K.H.; Hong, S.I. Dislocation creep behavior of CoCrFeMnNi high entropy alloy at intermediate temperatures. Mater. Res. Lett. 2018, 6, 689-695. [CrossRef]

19. Tirunilai, A.S.; Sas, J.; Weiss, K.-P.; Chen, H.; Szabó, D.V.; Schlabach, S.; Haas, S.; Geissler, D.; Freudenberger, J.; Heilmaier, M.; et al. Peculiarities of deformation of $\mathrm{CoCrFeMnNi}$ at cryogenic temperatures. J. Mater. Res. 2018, 33, 3287-3300. [CrossRef]

20. Sun, S.J.; Tian, Y.Z.; Lin, H.R.; Dong, X.G.; Wang, Y.H.; Zhang, Z.J.; Zhang, Z.F. Enhanced strength and ductility of bulk CoCrFeMnNi high entropy alloy having fully recrystallized ultrafine-grained structure. Mater. Des. 2017. [CrossRef]

21. Joseph, J.; Haghdadi, N.; Annasamy, M.; Kada, S.; Hodgson, P.D.; Barnett, M.R.; Fabijanic, D.M. On the enhanced wear resistance of $\mathrm{CoCrFeMnNi}$ high entropy alloy at intermediate temperature. Scr. Mater. 2020. [CrossRef]

22. Otto, F.; Dlouhý, A.; Pradeep, K.G.; Kuběnová, M.; Raabe, D.; Eggeler, G.; George, E.P. Decomposition of the single-phase high-entropy alloy $\mathrm{CrMnFeCoNi}$ after prolonged anneals at intermediate temperatures. Acta Mater. 2016, 112, 40-52. [CrossRef]

23. Vaidya, M.; Pradeep, K.G.; Murty, B.S.; Wilde, G.; Divinski, S.V. Bulk tracer diffusion in CoCrFeNi and CoCrFeMnNi high entropy alloys. Acta Mater. 2018. [CrossRef]

24. Tsai, K.Y.; Tsai, M.H.; Yeh, J.W. Sluggish diffusion in Co-Cr-Fe-Mn-Ni high-entropy alloys. Acta Mater. 2013. [CrossRef]

25. Kireeva, I.V.; Chumlyakov, Y.I.; Pobedennaya, Z.V.; Vyrodova, A.V.; Karaman, I. Twinning in [001]-oriented single crystals of CoCrFeMnNi high-entropy alloy at tensile deformation. Mater. Sci. Eng. A 2018, 713, 253-259. [CrossRef]

26. Abuzaid, W.; Sehitoglu, H. Critical resolved shear stress for slip and twin nucleation in single crystalline FeNiCoCrMn high entropy alloy. Mater. Charact. 2017, 129, 288-299. [CrossRef]

27. Patriarca, L.; Ojha, A.; Sehitoglu, H.; Chumlyakov, Y.I. Slip nucleation in single crystal FeNiCoCrMn high entropy alloy. Scr. Mater. 2016, 112, 54-57. [CrossRef]

28. Fleischmann, E.; Konrad, C.; Preußner, J.; Völkl, R.; Affeldt, E.; Glatzel, U. Influence of Solid Solution Hardening on Creep Properties of Single-Crystal Nickel-Based Superalloys. Metall. Mater. Trans. A Phys. Metall. Mater. Sci. 2015, 46, 1125-1130. [CrossRef]

29. Haas, S.; Mosbacher, M.; Senkov, O.; Feuerbacher, M.; Freudenberger, J.; Gezgin, S.; Völkl, R.; Glatzel, U. Entropy Determination of Single-Phase High Entropy Alloys with Different Crystal Structures over a Wide Temperature Range. Entropy 2018, 20, 654. [CrossRef]

30. Konrad, C.H.; Brunner, M.; Kyrgyzbaev, K.; Völkl, R.; Glatzel, U. Determination of heat transfer coefficient and ceramic mold material parameters for alloy IN738LC investment castings. J. Mater. Process. Technol. 2011, 211, 181-186. [CrossRef]

31. Fleischmann, E.; Miller, M.K.; Affeldt, E.; Glatzel, U. Quantitative experimental determination of the solid solution hardening potential of rhenium, tungsten and molybdenum in single-crystal nickel-based superalloys. Acta Mater. 2015, 87, 350-356. [CrossRef]

32. Mora-García, A.G.; Mosbacher, M.; Hastreiter, J.; Völkl, R.; Glatzel, U.; Muñoz-Saldaña, J. Creep behavior of polycrystalline and single crystal Ni-based superalloys coated with Ta-containing NiCoCrAlY by high-velocity oxy-fuel spraying. Scr. Mater. 2020, 178, 522-526. [CrossRef]

33. Kellner, P.M.; Völkl, R.; Glatzel, U. Influence of Ingot and Powder Metallurgy Production Route on the Tensile Creep Behavior of Mo-9Si-8B Alloys with Additions of Al and Ge. Adv. Eng. Mater. 2018, 20. [CrossRef]

34. Völkl, R.; Fischer, B.; Beschliesser, M.; Glatzel, U. Evaluating strength at ultra-high temperatures-Methods and results. Mater. Sci. Eng. A 2008, 483-484, 587-589. [CrossRef]

35. Haas, S.; Manzoni, A.M.; Krieg, F.; Glatzel, U. Microstructure and mechanical properties of precipitate strengthened high entropy alloy Al10Co25Cr8Fe15Ni36Ti6 with additions of Hafnium and molybdenum. Entropy 2019, 169. [CrossRef]

36. Rae, C.M.F.; Zhang, L. Primary creep in single crystal superalloys: Some comments on effects of composition and microstructure. Mater. Sci. Technol. 2009, 25, 228-235. [CrossRef] 
37. Tsuno, N.; Shimabayashi, S.; Kakehi, K.; Rae, C.M.F.; Reed, R.C. Tension/compression asymmetry in yield and creep strengths of ni-based superalloys. In Proceedings of the International Symposium on Superalloys, Champion, PA, USA, 14-18 September 2008; pp. 433-442.

38. Mackay, R.A.; Maier, R.D. The influence of orientation on the stress rupture properties of nickel-base superalloy single crystals. Metall. Mater. Trans. A 1982, 13, 1747-1754. [CrossRef]

39. Leverant, G.R.; Kear, B.H. The mechanism of creep in gamma prime precipitation-hardened nickel-base alloys at intermediate temperatures. Metall. Mater. Trans. B 1970, 1, 491-498. [CrossRef]

40. Caillard, D.; Martin, J.L. New trends in creep microstructural models for pure metals. Rev. Phys. Appliquée 1987, 22, 169-183. [CrossRef]

41. Ashby, M.F.; Frost, H.J. Deformation-Mechanism Maps; Pergamon Press: Oxford, UK, 1982.

42. Cao, C.; Fu, J.; Tong, T.; Hao, Y.; Gu, P.; Hao, H.; Peng, L. Intermediate-temperature creep deformation and microstructural evolution of an equiatomic FCC-structured CoCrFeNiMn high-entropy alloy. Entropy 2018, 960. [CrossRef]

Publisher's Note: MDPI stays neutral with regard to jurisdictional claims in published maps and institutional affiliations.

(C) 2020 by the authors. Licensee MDPI, Basel, Switzerland. This article is an open access article distributed under the terms and conditions of the Creative Commons Attribution (CC BY) license (http://creativecommons.org/licenses/by/4.0/). 